\title{
Protective Effects of the Flavonoid Chrysin against Methylmercury-Induced Genotoxicity and Alterations of Antioxidant Status, In Vivo
}

\author{
Eduardo Scandinari Manzolli, ${ }^{1}$ Juliana Mara Serpeloni, ${ }^{1}$ Denise Grotto, ${ }^{1}$ \\ Jairo Kennup Bastos, ${ }^{2}$ Lusânia Maria Greggi Antunes, ${ }^{1}$ \\ Fernando Barbosa Jr., ${ }^{1}$ and Gustavo Rafael Mazzaron Barcelos ${ }^{1}$ \\ ${ }^{1}$ Department of Clinical Analyses, Toxicology and Food Sciences, School of Pharmaceutical Sciences of Ribeirão Preto, \\ University of São Paulo, Avenida do Café s/n, 14040-903 Ribeirão Preto, SP, Brazil \\ ${ }^{2}$ Department of Pharmaceutical Sciences, School of Pharmaceutical Sciences of Ribeirão Preto, University of São Paulo, \\ Avenida do Café s/n, 14040-903 Ribeirão Preto, SP, Brazil
}

Correspondence should be addressed to Gustavo Rafael Mazzaron Barcelos; barcelos@fcfrp.usp.br

Received 10 December 2014; Revised 10 February 2015; Accepted 11 February 2015

Academic Editor: Silvana Hrelia

Copyright (C) 2015 Eduardo Scandinari Manzolli et al. This is an open access article distributed under the Creative Commons Attribution License, which permits unrestricted use, distribution, and reproduction in any medium, provided the original work is properly cited.

\begin{abstract}
The use of phytochemicals has been widely used as inexpensive approach for prevention of diseases related to oxidative damage due to its antioxidant properties. One of dietary flavonoids is chrysin (CR), found mainly in passion fruit, honey, and propolis. Methylmercury $(\mathrm{MeHg})$ is a toxic metal whose main toxic mechanism is oxidative damage. Thus, the study aimed to evaluate the antioxidant effects of CR against oxidative damage induced by $\mathrm{MeHg}$ in Wistar rats. Animals were treated with $\mathrm{MeHg}(30 \mu \mathrm{g} / \mathrm{kg} / \mathrm{bw})$ in presence and absence of CR $(0.10,1.0$, and $10 \mathrm{mg} / \mathrm{kg} / \mathrm{bw})$ by gavage for 45 days. Glutathione (GSH) in blood was quantified spectrophotometrically and for monitoring of DNA damage, comet assay was used in leukocytes and hepatocytes. MeHg led to a significant increase in the formation of comets; when the animals were exposed to the metal in the presence of CR, higher concentrations of CR showed protective effects. Moreover, exposure to MeHg decreased the levels of GSH and GSH levels were restored in the animals that received CR plus MeHg. Taken together the findings of the present work indicate that consumption of flavonoids such as CR may protect humans against the adverse health effects caused by $\mathrm{MeHg}$.
\end{abstract}

\section{Introduction}

The use of phytochemicals (PhC) has been proposed as inexpensive approach for prevention of diseases associated with oxidative stress, such as cardiovascular disorders, degenerative diseases, and cancer, due to its antioxidant properties [1-3]. PhC are bioactive compounds, nonnutrients found in fruits, vegetables, grains, and other plants that are associated with a decreased risk to develop several diseases [1]. In this context, it is notable that several studies have been carried out aiming to assess the potential protective effects of $\mathrm{PhC}$ in many laboratory models, showing very promising results [3-7].
The flavonoid chrysin (CR; 5,7-dihydroxy-2-phenyl-4Hchromen-4-one) is a natural and biologically active compound; it is found mainly in honey, passion fruit (Passiflora sp.), and propolis [8-10]. Previous studies were already performed aiming to determine the concentrations of CR in honey and propolis; for example, Lachman et al. [11] assessed the CR content in several types of honeys and found values ranging from $0.10 \mathrm{mg} / \mathrm{kgg}$ (honeydew honeys) to $5.3 \mathrm{mg} / \mathrm{kg}$ (forest honeys); in another study, Siess et al. [12] found levels of CR in propolis as high as $28 \mathrm{~g} / \mathrm{L}$, demonstrating that honey and propolis are a rich source of this flavonoid.

Compared with other flavonoids, few studies have been carried out in order to determine the beneficial effects of CR. 
Some of these investigations yielded promising results. For example, Uhl et al. [13] demonstrated antimutagenic properties against benzo(a)pyrene $\mathrm{B}(\mathrm{a}) \mathrm{P}$ induced DNA-damage in HepG2 cells and Salmonella typhimurium; Anand et al. [14] showed that $\mathrm{CR}$ reduces the disturbances of redox status, named superoxide dismutase (SOD), catalase (CAT), glutathione peroxidase (GPx), and glutathione (GSH) in liver, kidney, and brain tissues of rats treated with D-galactose.

Fish is considered a healthy food since it is a good source of proteins, is poor in saturated fats, and has high amounts of polyunsaturated fat acids, which may protect against cardiovascular disorders; and populations that traditionally consume large amounts of fish generally show low mortality rates from coronary diseases $[15,16]$. On the other hand, fish consumption is also an important source of human exposure to a variety of bioactive toxicants such as methylmercury (MeHg) and arsenic (As) [17-19] which may interact with the health effects of fish intake [20-22]. It is well established that chronic exposure to $\mathrm{MeHg}$ is associated with neurological disorders [23-25] and with adverse effects on the cardiovascular system $[26,27]$. One of the main mechanisms responsible for $\mathrm{MeHg}$ toxicity is the induction of oxidative stress. Earlier data have consistently shown that $\mathrm{MeHg}$ exposure can lead to disturbances in the redox status, causing oxidative damage in macromolecules, such as lipids and DNA $[28,29]$.

Despite the low number of studies concerned with evaluating the protective effects of $\mathrm{PhC}$ against $\mathrm{MeHg}$-induced adverse effects, the aim of present study was to investigate potential protective effects of CR against the toxic effects caused by $\mathrm{MeHg}$, through monitoring of DNA-damage by comet assays in peripheral blood cells and hepatocytes and by determination of GSH levels in blood of Wistar rats.

\section{Materials and Methods}

2.1. Chemicals. Methylmercury chloride (CAS 115-09-3), reduced glutathione (GSH, CAS 70-18-8), glutathione reductase (GR, CAS 9001-48-3), sodium azide (CAS 26628-22-8), trypan blue (CAS 72-57-1), ethidium bromide (CAS 123945-8), and 5-5' -dithiobis-(2-nitrobenzoic acid) (DTNB; CAS 69-78-3) came from Sigma-Aldrich (St. Louis, MO, USA). CR (CAS 480-40-8) was kindly provided by Professor Dr. Jairo K. Bastos from School of Pharmaceutical Sciences of Ribeirão Preto, São Paulo, Brazil. The purity of CR used in the experiments was $\geq 95 \%$. Ketamine and xylazine were from Bayer (São Paulo, Brazil). Low melting point agarose (LMP) and normal melting point (NMP) agarose were obtained from Invitrogen (California, CA, USA). All other chemicals, reagents, and buffers were analytical grade products from Sigma (St. Louis, MO, USA).

2.2. Animals. The experiments were carried out with 2 month-old male Wistar rats, weighing on average $200 \pm 20$ g, which were obtained from Central Animal House (University of São Paulo, Ribeirão Preto, Brazil). The animals were kept under a $12 \mathrm{~h}$ light/dark cycle in an acclimatized room at $22-25^{\circ} \mathrm{C}$ and had free access to food (standard ration from Guabi, Campinas, Brazil) and water. The animals were used according to the guidelines of the Committee on Care and
Use of Experimental Animal Resources, University of São Paulo, Brazil (approved protocol number 09.1.457.53.1).

2.3. Experimental Design. The dose of $\mathrm{MeHg}(30 \mu \mathrm{g} / \mathrm{kg}$ of body weight (bw)) was chosen on the basis of previous studies of our group which showed consistently that this concentration is able to induce DNA damage and disturbances of redox status and also reflects the exposure levels of individuals from Amazonian region [30-32] and from other regions which also have high levels of MeHg exposure [33]. Treatments with CR were chosen according to previous articles [14, 34].

The animals were divided in eight groups (six animals/group): (I) control (mineral oil); (II) $\mathrm{MeHg}$ $(30 \mu \mathrm{g} / \mathrm{kg} \mathrm{bw}) ; \quad$ (III) CR I $(0.10 \mathrm{mg} / \mathrm{kg} \mathrm{bw}) ;$ (IV) CR II (1.0 mg/kg bw); (V) CR III (10 mg/kg bw); (VI) CR I + MeHg; (VII) CR II + MeHg; and (VIII) CR III + MeHg; the animals were treated daily by gavage for a period of 45 days. After the treatment, the rats were killed by an overdose of ketamine and xylazine (300 and $30.0 \mathrm{mg} / \mathrm{kg}$ bw, resp.). Subsequently, blood was collected by decapitation and used for comet analyses and to determine the GSH levels. The livers were rinsed with phosphate buffered saline (PBS, pH 7.4) before removal.

\subsection{Comet Assays with Peripheral Leukocytes and Hepato-} cytes. Whole blood was used for the determination of DNA damage in leukocytes [35]. Samples of liver were collected after euthanasia, and $0.20 \mathrm{~g}$ of each organ was placed in $1.0 \mathrm{~mL}$ of chilled Hank's balanced salt solution in a Petri dish, sliced into fragments with a pair of scissors, and filtered through two layers of gauze [36].

The SCGE assays were carried out according to the protocol of Singh et al. [37]. Briefly, $20 \mu \mathrm{L}$ of blood or nuclei from liver suspensions was transferred to agarosecoated slides which were coverslipped and cooled at $4^{\circ} \mathrm{C}$ for $20 \mathrm{~min}$. After removal of the coverslips, the slides were immersed in fresh lysis solution for $1 \mathrm{~h}$ at $4^{\circ} \mathrm{C}$. Thereafter, they were transferred to an electrophoresis chamber with buffer $(300 \mathrm{mM} \mathrm{NaOH}$ and $1.0 \mathrm{mM}$ EDTA $\mathrm{pH}>13$ ) and electrophoresis was conducted under standard conditions $(25 \mathrm{~V} ; 300 \mathrm{~mA} ; 1.25 \mathrm{~V} / \mathrm{cm})$ for $20 \mathrm{~min}$. Subsequently, the slides were neutralized, air-dried, and fixed in absolute ethanol for 10 minutes; then they were stained with ethidium bromide and evaluated with a fluorescence microscope (Nikon, Japan) under 40x magnification. From each sample, two slides were made and from each, 50 cells were evaluated per animal. Comets were scored using the Comet Score software from Tritek (Sumerduck, VA, USA); the percentage of DNA in tail was determined as a parameter of DNA damage. All experiments were carried out according to the guidelines for SCGE assays [36]. The trypan dye exclusion method [38] was used to determine cell viability immediately before the comet assays and 300 cells were evaluated per group. In all treatments, the viability was higher than $80 \%$.

2.5. Total Thiols (GSH) Levels. Total thiols (taken here as GSH) were determined in erythrocytes by addition of DTNB as described by Ellman [39]. DTNB, a symmetric aryl disulfide, reacts with free thiols to form disulfide plus 2-nitro5 -thiobenzoic acid. The reaction product was quantified by 
measurement of absorbance at $412 \mathrm{~nm}$ with a spectrophotometer (Micronal B380 UV-Vis, São Paulo, Brazil). Results are expressed as micromoles per milliliter $(\mu \mathrm{mol} / \mathrm{mL})$ in blood.

2.6. Statistical Analysis. All data analyses were performed with the GraphPad Prism version 6.01 for Windows (La Jolla, CA, USA). Results are reported as means \pm standard deviations (SD). The results of different experiments were analyzed using one-way ANOVA and Dunnett's test. $P$ values $\leq 0.050$ were considered as statistically significant.

\section{Results}

The results of the experiments concerning the impact of $\mathrm{CR}$ on MeHg-induced comet formation are summarized in Figure 1. Exposure of the animals to the metal compound increased the extent of DNA-migration in leukocytes and liver cells 9.3 and 4.9-fold over the background values while all treatments with CR did not cause significant DNA-damage under our experimental conditions. Comet formation was significantly reduced when the flavonoid was administered in combination with the metal. In leukocytes, the decrease of comet formation at the highest doses $(1.0$ and $10 \mathrm{mg} / \mathrm{mL})$ was 33 and $35 \%$, respectively, while in hepatocytes only the highest dose was able to reduce $\mathrm{MeHg}$ induced DNA-damage.

The results of the measurements of the GSH levels in blood are summarized in Figure 2. Treatment with the metal reduced the levels of GSH when compared to negative controls. Furthermore, it can be seen that treatment with the higher doses of CR had a clear impact on the GSH concentrations and reduced the GSH concentrations by 15 and $16 \%$, respectively.

Figure 2 also shows the levels of the tripeptide GSH which were measured after combined treatment of the animals with $\mathrm{MeHg}$ and different doses of the flavonoid. When the animals were exposed simultaneously to the metal compound and to $\mathrm{CR}$, the GSH concentrations were restored to those found in untreated control animals.

\section{Discussion}

Taken together, the findings of the present work indicate that consumption of flavonoids such as CR may protect humans against the adverse health effects caused by exposure to $\mathrm{MeHg}$.

The observation of comet formation in white blood cells and hepatocytes of the animals after treatment with $\mathrm{MeHg}$ is in agreement with results of earlier studies [31, $32,40]$. In addition, we demonstrated previously that $\mathrm{MeHg}$ increases the formation of 8-hydroxy- $2^{\prime}$-deoxyguanosine in HepG2 cells [5]. Jin et al. [41] also observed increase of this parameter in rats that were exposed to the metal compound. These findings give pieces of evidence that oxidative damage accounts for the comet formation which we observed in the present study.

In vitro results concerning the genotoxic properties of CR are, so far, contradictory and are related to the models that were used. For example, Resende et al. [42] showed that concentrations between 14.3 and $174.7 \mathrm{nmol} /$ plate were not able to induce mutagenic effects in Salmonella typhimurium TA 98 and TA 100 with or without S9 fraction. On the other hand, Uhl et al. [13] demonstrated that CR induces $\mathrm{MN}$ formation in HepG2 cells in doses ranging from 15 to $35 \mu \mathrm{g} / \mathrm{mL}$; also, Oliveira et al. [43] reported increase of MN induction in HepG2 cells exposed to the flavonoid $(1.0-15 \mu \mathrm{M})$. In the same work, the later authors found that high doses of CR are able to induce mutagenic effects in $S$. typhimurium TA 98 and TA 100 (with or without S9 fraction). Resende et al. [42] reported that higher concentrations of CR (116.4 and $174.7 \mathrm{nmol} / \mathrm{plate})$ induce significant number of revertants per plate in S. typhimurium TA 102. In this context, it is notable that flavonoids and other phytochemicals may act as prooxidants at high concentrations $[44,45]$.

Despite the large number of in vitro studies which aimed to assess the genotoxicity of CR, to our knowledge, there are no in vivo studies and there are no works that evaluated the potential genotoxic effects of CR on animals in subchronic treatments as the present study. Here, we observed that CR was not able to induce comet formation in all doses tested. This difference between the observations in mammal cells culture, such as HepG2, and the present data may be explained, at least partly, to the metabolism system of them. HepG2 cells possess mainly high expression of enzymes of phase I of metabolism [46]; the same occurs in systems that used the S9 fraction (which also have high levels of phase I enzymes) [47], while in animals, the metabolism comprises a balanced expression of phase I and phase II enzymes [48].

It is well documented in in vitro and in vivo experiments that $\mathrm{MeHg}$ exposure leads to formation of reactive species that may cause oxidative damage of macromolecules [28, 29]. Furthermore, it was also shown that the $\mathrm{MeHg}$ binds to endogenous biomolecules with -SH groups; this observation explains the decrease of the GSH levels which was seen in the present experiments and is in accordance with previous studies $[49,50]$.

One of the most important mechanisms to explain the oxidative damage induced by $\mathrm{Hg}$ exposure is its high reactivity with sulhydryl groups $(-\mathrm{SH})$ of macromolecules, which may inactivate them [51]. GSH is the main intracellular nonprotein free thiol, and it is also one of the most important antioxidants in the body [52]. It is conceived that GSH play a role as a first cellular defense against $\mathrm{Hg}$ compounds. The metal compounds bind to GSH covalently, through cysteine residues and thus, its deleterious effects are minimized. This protective effect mediated by GSH, however, decreases its concentrations, and then the cells may be more susceptible to oxidative damage through the accumulation of reactive oxygen species (ROS) normally neutralized by GSH $[53,54]$.

The reactive species then attack proteins, DNA and lipids [55], inducing oxidative damage. $\mathrm{Hg}$ interferes with the activity of several antioxidant enzymes; for example, the activity of superoxide dismutase (SOD), catalase (CAT), and glutathione peroxidase (GPx). However, so far, there is no general consensus among the data; that is, some studies reported increase of activity of certain antioxidant enzymes while others showed a reduction in activity of these enzymes. Ariza et al. [40] demonstrated that $\mathrm{HgCl}_{2}$, inducing the 


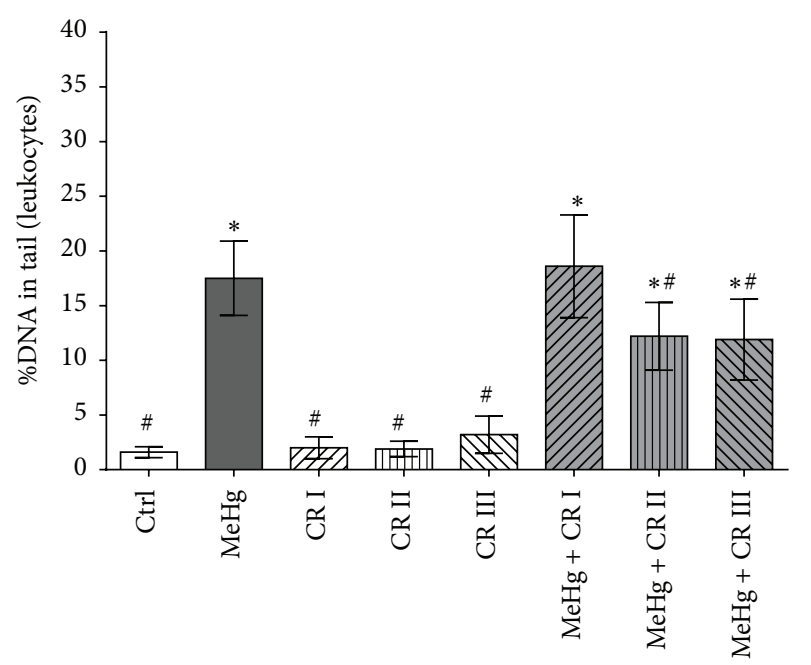

(a)

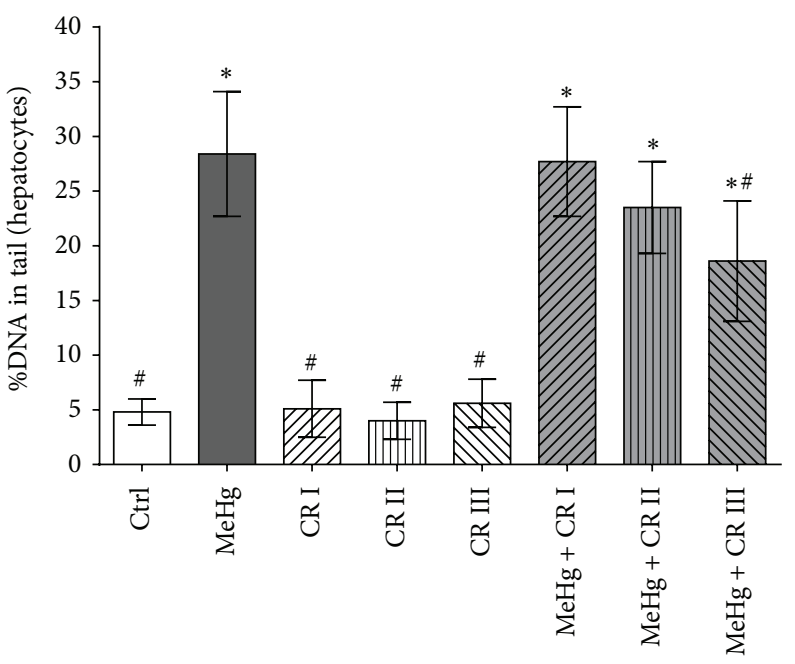

(b)

FIGURE 1: Impact of oral treatment of rats with CR on induction of DNA-damage by MeHg in (a) lymphocytes and (b) hepatocytes. The animals were treated by gavage with different doses of the flavonoid (CR I: $0.1 \mathrm{mg} / \mathrm{kg} / \mathrm{bw} / \mathrm{day}$; CR II: $1.0 \mathrm{mg} / \mathrm{kg} / \mathrm{bw} / \mathrm{day}$; and CR III $10 \mathrm{mg} / \mathrm{kg} / \mathrm{bw} / \mathrm{day}$ ) in combination with the metal $(30 \mu \mathrm{g} / \mathrm{kg} / \mathrm{bw} /$ day $)$ over a period of 45 days. Bars indicate means \pm SD of results obtained with six animals per group. Stars indicate significant difference from negative control group; hashes indicate significant difference in comparison to the MeHg group ( $P \leq 0.050$; one-way ANOVA and Dunnett's test).

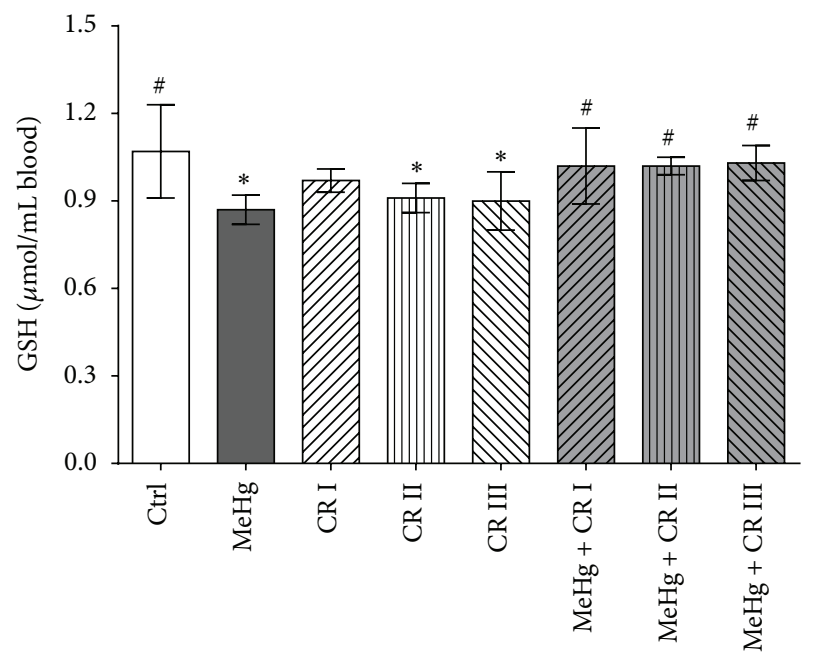

FIGURE 2: Impact of oral treatment of rats with $\mathrm{CR}$ on the levels of GSH in blood. The animals were treated by gavage with different doses of the flavonoid (CR I: $0.1 \mathrm{mg} / \mathrm{kg} / \mathrm{bw} /$ day; CR II: $1.0 \mathrm{mg} / \mathrm{kg} / \mathrm{bw} /$ day; and CR III $10 \mathrm{mg} / \mathrm{kg} / \mathrm{bw} /$ day) in combination with the metal $(30 \mu \mathrm{g} / \mathrm{kg} / \mathrm{bw} /$ day $)$ over a period of 45 days. Bars indicate means \pm SD of results obtained with six animals per group. Stars indicate significant difference from negative control group; hashes indicate significant difference in comparison to the $\mathrm{MeHg}$ group $(P \leq 0.050$; one-way ANOVA and Dunnett's test).

formation of $\mathrm{H}_{2} \mathrm{O}_{2}$, stimulates SOD activity and does not affect the activity of CAT and GPx, whereas Hussain et al. [56] showed an increase in the activity of GPx and CAT. In general, acute exposure to $\mathrm{Hg}$ leads to decrease in enzymatic activity; on the other hand, exposure to prolonged periods seems to not change the enzyme patterns, possibly due to an indirect compensatory response of the cells to increased oxidative stress, such as self-protection mechanism [49].

We also showed that the higher doses of CR (1.0 and $10 \mathrm{mg} / \mathrm{kg}$ bw, resp.) reduce the levels of GSH when compared to negative controls. A possible explanation for this observation is that antioxidant properties of CR may modulate a feedback mechanism on the antioxidant system triggered by administration of the flavonoid to the animals, which was already seen in a previous study where female rats were exposed to several flavonoids, including CR [57].

The expectation that CR prevents the adverse effects of $\mathrm{MeHg}$ is based on results of previous studies which indicate that the flavonoid shows DNA-protective effects against radiation and chemically induced DNA-instability. For example, Benković et al. [58] showed that CR at dose of $100 \mathrm{mg} / \mathrm{kg}$ bw was able to decrease the comet formation in leukocytes of gamma-irradiated mice; in a further study of the same authors [59] it was observed that pretreatment of CR protects against DNA-damage induced by gamma radiation in human lymphocytes cell cultures. Uhl and coworkers [13] observed that CR decreases MN formation induced by $\mathrm{B}(\mathrm{a}) \mathrm{P}$ and 2amino-1-methyl-6-phenylimidazo[4,5-b]pyridine exposure. In the same study, the authors also observed protective effects in S. typhimurium strains TA 98 and TA 100 against $\mathrm{B}(\mathrm{a}) \mathrm{P}$. A recent study of Resende et al. [60] gives further pieces of evidence concerning the antigenotoxic effects of $\mathrm{CR}$ against several indirect and direct mutagens (4-nitroo-phenylenediamine, sodium azide, mitomycin C, B(a)P, aflatoxin B1 and 2-anthramine) in S. typhimurium TA 98, 100 , and 102, with or without activation mix (S9). Another hypothesis is that $\mathrm{CR}$ can bind directly to $\mathrm{MeHg}$, chelating the metal, and prevent the direct oxidative damage induced by exposure to the metal, which was already reported by several studies (for a comprehensive review, see Flora 2009; 2010) 
$[61,62]$. These previous findings give further support that flavonoids may act not only as direct antioxidant, inactivating free radicals, but also as an attractive tool for prevention of adverse health effects induced by heavy metals by use of chelation therapy.

Finally, we also observed that CR ameliorated the disturbances in the levels of GSH induced by $\mathrm{MeHg}$ exposure; in line with our findings, several studies consistently showed the antioxidant properties of CR. Ciftci et al. [63, 64] observed that the flavonoid was able to reduce the alterations on the antioxidant enzymes SOD, CAT, and GPx and on the levels of GSH in kidneys and livers of mice treated with 2,3,7,8tetrachlorodibenzo- $p$-dioxin. In another study, Siess et al. [12] showed that CR reduces the disturbances of the redox status in liver, kidney, and brain tissues of rats which were induced with D-galactose.

As mentioned above, it is conceivable that the adverse health effects caused by $\mathrm{MeHg}$ in humans are due to oxidative damage. Therefore, studies which aim to evaluate the protective effects of food-compounds that can counteract the $\mathrm{MeHg}$-induced oxidative damage in macromolecules, such as in DNA, are in need to have a better knowledge about the mechanisms that these compounds counteract the adverse effects induced by the metal and consequently may help to protect populations that are exposed chronically to $\mathrm{MeHg}$.

\section{Conclusions}

The present study is the first which concerns the protective effects of the flavonoid CR against DNA-damage induced by exposure of $\mathrm{MeHg}$ in vivo. The results give further support about the fact that CR itself does not cause adverse health effects in mammals and indicate that flavonoid may protect against DNA-damage and disturbances in redox status induced by the metal compound.

\section{Conflict of Interests}

The authors declare that they have no conflict of interests.

\section{Acknowledgments}

The authors thank the São Paulo Research Foundation (FAPESP), the National Council for Technological and Scientific Development (CNPq), Coordination for the Improvement of Higher Education Personnel (CAPES), and University of São Paulo (USP) for financial support.

\section{References}

[1] R. H. Liu, "Health benefits of fruit and vegetables are from additive and synergistic combinations of phytochemicals," The American Journal of Clinical Nutrition, vol. 78, supplement 3, pp. S517-S520, 2003.

[2] Y. J. Surh, "Cancer chemoprevention with dietary phytochemicals," Nature Reviews Cancer, vol. 3, no. 10, pp. 768-780, 2003.

[3] T. M. de Kok, S. G. van Breda, and M. M. Manson, "Mechanisms of combined action of different chemopreventive dietary compounds: a review," European Journal of Nutrition, vol. 47, supplement 2, pp. 51-59, 2008.

[4] M.-T. Huang, R. L. Chang, A. W. Wood et al., "Inhibition of the mutagenicity of bay-region diol-epoxides of polycyclic aromatic hydrocarbons by tannic acid, hydroxylated anthraquinones and hydroxylated cinnamic acid derivatives," Carcinogenesis, vol. 6 , no. 2, pp. 237-242, 1985.

[5] G. R. M. Barcelos, J. P. F. Angeli, J. M. Serpeloni et al., "Quercetin protects human-derived liver cells against mercury-induced DNA-damage and alterations of the redox status," Mutation Research/Genetic Toxicology and Environmental Mutagenesis, vol. 726, no. 2, pp. 109-115, 2011.

[6] J. M. Serpeloni, G. R. M. Barcelos, J. P. Friedmann Angeli, A. Z. Mercadante, M. Lourdes Pires Bianchi, and L. M. Greggi Antunes, "Dietary carotenoid lutein protects against DNA damage and alterations of the redox status induced by cisplatin in human derived HepG2 cells," Toxicology in Vitro, vol. 26, no. 2, pp. 288-294, 2012.

[7] Z. Sahhugi, S. M. Hasenan, and Z. Jubri, "Protective effects of gelam honey against oxidative damage in young and aged rats," Oxidative Medicine and Cellular Longevity, vol. 2014, Article ID 673628, 8 pages, 2014.

[8] E. Brown, N. S. Hurd, S. McCall, and T. E. Ceremuga, "Evaluation of the anxiolytic effects of chrysin, a Passiflora incarnata extract, in the laboratory rat," AANA Journal, vol. 75, no. 5, pp. 333-337, 2007.

[9] S. K. Jaganathan and M. Mandal, "Antiproliferative effects of honey and of its polyphenols: a review," Journal of Biomedicine and Biotechnology, vol. 2009, Article ID 830616, 13 pages, 2009.

[10] P. Premratanachai and C. Chanchao, "Review of the anticancer activities of bee products," Asian Pacific Journal of Tropical Biomedicine, vol. 4, no. 5, pp. 337-344, 2014.

[11] J. Lachman, A. Hejtmánková, J. Sýkora, J. Karban, M. Orsák, and B. Rygerová, "Contents of major phenolic and flavonoid antioxidants in selected Czech honey," Czech Journal of Food Sciences, vol. 28, no. 5, pp. 412-426, 2010.

[12] M.-H. Siess, A.-M. Le Bon, M.-C. Canivenc-Lavier et al., "Flavonoids of honey and propolis: characterization and effects on hepatic drug-metabolizing enzymes and benzo[a]pyreneDNA binding in rats," Journal of Agricultural and Food Chemistry, vol. 44, no. 8, pp. 2297-2301, 1996.

[13] M. Uhl, S. Ecker, F. Kassie et al., "Effect of chrysin, a flavonoid compound, on the mutagenic activity of 2-amino-1-methyl6-phenylimidazo[4,5-b]pyridine (PhIP) and benzo(a)pyrene (B(a)P) in bacterial and human hepatoma (HepG2) cells," Archives of Toxicology, vol. 77, no. 8, pp. 477-484, 2003.

[14] K. V. Anand, M. S. Mohamed Jaabir, P. A. Thomas, and P. Geraldine, "Protective role of chrysin against oxidative stress in d-galactose-induced aging in an experimental rat model," Geriatrics and Gerontology International, vol. 12, no. 4, pp. 741750,2012

[15] B. E. Millen and P. A. Quatromoni, "Nutritional research within the Framingham Heart Study," The Journal of Nutrition Health and Aging, vol. 5, no. 3, pp. 139-143, 2001.

[16] S. P. Whelton, J. He, P. K. Whelton, and P. Muntner, "Metaanalysis of observational studies on fish intake and coronary heart disease," The American Journal of Cardiology, vol. 93, no. 9, pp. 1119-1123, 2004.

[17] T. W. Clarkson, "The three modern faces of mercury," Environmental Health Perspectives, vol. 110, supplement 1, pp. 11-23, 2002. 
[18] T. W. Clarkson and L. Magos, "The toxicology of mercury and its chemical compounds," Critical Reviews in Toxicology, vol. 36, no. 8, pp. 609-662, 2006.

[19] A. M. Višnjevec, D. Kocman, and M. Horvat, "Human mercury exposure and effects in Europe," Environmental Toxicology and Chemistry, vol. 33, no. 6, pp. 1259-1270, 2014.

[20] H. M. Chan and G. M. Egeland, "Fish consumption, mercury exposure, and heart diseases," Nutrition Reviews, vol. 62, no. 2, pp. 68-72, 2004.

[21] D. Grotto, J. Valentini, J. M. Serpeloni et al., "Evaluation of toxic effects of a diet containing fish contaminated with methylmercury in rats mimicking the exposure in the Amazon riverside population," Environmental Research, vol. 111, no. 8, pp. 10741082, 2011.

[22] A. H. Stern, "A review of the studies of the cardiovascular health effects of methylmercury with consideration of their suitability for risk assessment," Environmental Research, vol. 98, no. 1, pp. 133-142, 2005.

[23] S. A. Counter and L. H. Buchanan, "Mercury exposure in children: a review," Toxicology and Applied Pharmacology, vol. 198, no. 2, pp. 209-230, 2004.

[24] C. Johansson, A. F. Castoldi, N. Onishchenko, L. Manzo, M. Vahter, and S. Ceccatelli, "Neurobehavioural and molecular changes induced by methylmercury exposure during development," Neurotoxicity Research, vol. 11, no. 3-4, pp. 241-260, 2007.

[25] M. R. Karagas, A. L. Choi, E. Oken et al., "Evidence on the human health effects of low-level methylmercury exposure," Environmental Health Perspectives, vol. 120, no. 6, pp. 799-806, 2012.

[26] A. L. Choi, P. Weihe, E. Budtz-Jørgensen et al., "Methylmercury exposure and adverse cardiovascular effects in Faroese whaling men," Environmental Health Perspectives, vol. 117, no. 3, pp. 367372, 2009.

[27] M. C. Houston, "Role of mercury toxicity in hypertension, cardiovascular disease, and stroke," The Journal of Clinical Hypertension, vol. 13, no. 8, pp. 621-627, 2011.

[28] M. Farina, M. Aschner, and J. B. T. Rocha, "Oxidative stress in MeHg-induced neurotoxicity," Toxicology and Applied Pharmacology, vol. 256, no. 3, pp. 405-417, 2011.

[29] D. Joshi, M. D. Kumar, S. A. Kumar, and S. Sangeeta, "Reversal of methylmercury-induced oxidative stress, lipid peroxidation, and DNA damage by the treatment of N-acetyl cysteine: a protective approach," Journal of Environmental Pathology, Toxicology and Oncology, vol. 33, no. 2, pp. 167-182, 2014.

[30] C. J. S. Passos, D. S. da Silva, M. Lemire et al., "Daily mercury intake in fish-eating populations in the Brazilian Amazon," Journal of Exposure Science and Environmental Epidemiology, vol. 18, no. 1, pp. 76-87, 2008.

[31] G. R. M. Barcelos, D. Grotto, J. M. Serpeloni et al., "Protective properties of quercetin against DNA damage and oxidative stress induced by methylmercury in rats," Archives of Toxicology, vol. 85, no. 9, pp. 1151-1157, 2011.

[32] G. R. M. Barcelos, D. Grotto, J. M. Serpeloni et al., "Bixin and norbixin protect against DNA-damage and alterations of redox status induced by methylmercury exposure in vivo," Environmental and Molecular Mutagenesis, vol. 53, no. 7, pp. 535-541, 2012.

[33] B. E. Lee, Y. C. Hong, H. Park et al., "Interaction between GSTM1/GSTT1 polymorphism and blood mercury on birth weight," Environmental Health Perspectives, vol. 118, no. 3, pp. 437-443, 2010.
[34] P. L. Sequetto, T. T. Oliveira, Í. A. C. Soares et al., “The flavonoid chrysin attenuates colorectal pathological remodeling reducing the number and severity of pre-neoplastic lesions in rats exposed to the carcinogen 1,2-dimethylhydrazine," Cell and Tissue Research, vol. 352, no. 2, pp. 327-339, 2013.

[35] J. da Silva, T. R. O. de Freitas, V. Heuser, J. R. Marinho, and B. Erdtmann, "Genotoxicity biomonitoring in coal regions using wild rodent Ctenomys torquatus by comet assay and micronucleus test," Environmental and Molecular Mutagenesis, vol. 35, no. 4, pp. 270-278, 2000.

[36] A. Hartmann, E. Agurell, C. Beevers et al., "Recommendations for conducting the in vivo alkaline comet assay," Mutagenesis, vol. 18, no. 1, pp. 45-51, 2003.

[37] N. P. Singh, M. T. McCoy, R. R. Tice, and E. L. Schneider, "A simple technique for quantitation of low levels of DNA damage in individual cells," Experimental Cell Research, vol. 175, no. 1, pp. 184-191, 1988.

[38] W. Strober, "Appendix 3B Trypan blue exclusion test of cell viability," Current Protocols in Immunology, 2001.

[39] G. L. Ellman, “Tissue sulfhydryl groups," Archives of Biochemistry and Biophysics, vol. 82, no. 1, pp. 70-77, 1959.

[40] M. E. Ariza, G. N. Bijur, and M. V. Williams, "Lead and mercury mutagenesis: role of $\mathrm{H}_{2} \mathrm{O}_{2}$, superoxide dismutase, and xanthine oxidase," Environmental and Molecular Mutagenesis, vol. 31, no. 4, pp. 352-361, 1998.

[41] X. Jin, H. M. Chan, E. Lok et al., "Dietary fats modulate methylmercury-mediated systemic oxidative stress and oxidative DNA damage in rats," Food and Chemical Toxicology, vol. 46, no. 5, pp. 1706-1720, 2008.

[42] F. A. Resende, W. Vilegas, L. C. Dos Santos, and E. A. Varanda, "Mutagenicity of flavonoids assayed by bacterial reverse mutation (Ames) test," Molecules, vol. 17, no. 5, pp. 5255-5268, 2012.

[43] G. A. R. Oliveira, E. R. A. Ferraz, A. O. Souza, R. A. Lourenço, D. P. Oliveira, and D. J. Dorta, "Evaluation of the mutagenic activity of chrysin, a flavonoid inhibitor of the aromatization process," Journal of Toxicology and Environmental Health, Part A, vol. 75, no. 16-17, pp. 1000-1011, 2012.

[44] D. Procházková, I. Boušová, and N. Wilhelmová, "Antioxidant and prooxidant properties of flavonoids," Fitoterapia, vol. 82, no. 4, pp. 513-523, 2011.

[45] H. Y. Khan, H. Zubair, M. F. Ullah, A. Ahmad, and S. M. Hadi, "A prooxidant mechanism for the anticancer and chemopreventive properties of plant polyphenols," Current Drug Targets, vol. 13, no. 14, pp. 1738-1749, 2012.

[46] N. J. Hewitt and P. Hewitt, "Phase I and II enzyme characterization of two sources of HepG2 cell lines," Xenobiotica, vol. 34, no. 3, pp. 243-256, 2004.

[47] G. Reifferscheid and S. Buchinger, "Cell-based genotoxity testing," in Whole Cell Sensing System II, S. Belkin and M. B. Gu, Eds., pp. 113-156, Springer, 2012.

[48] J. A. Timbrell and T. C. Marrs, "Biotransformation of xenobiotics," in General, Applied and Systems Toxicology, John Wiley \& Sons, New York, NY, USA, 2009.

[49] C. Chen, L. Qu, B. Li et al., "Increased oxidative DNA damage, as assessed by urinary 8 -hydroxy-2l-deoxyguanosine concentrations, and serum redox status in persons exposed to mercury," Clinical Chemistry, vol. 51, no. 4, pp. 759-767, 2005.

[50] D. Grotto, J. Valentini, M. Fillion et al., "Mercury exposure and oxidative stress in communities of the Brazilian Amazon," Science of the Total Environment, vol. 408, no. 4, pp. 806-811, 2010. 
[51] F. Schurz, M. Sabater-Vilar, and J. Fink-Gremmels, "Mutagenicity of mercury chloride and mechanisms of cellular defence: the role of metal-binding proteins," Mutagenesis, vol. 15, no. 6, pp. 525-530, 2000.

[52] R. J. Singh, "Glutathione: a marker and antioxidant for aging," Journal of Laboratory and Clinical Medicine, vol. 140, no. 6, pp. 380-381, 2002.

[53] T. A. Sarafian, "Methylmercury-induced generation of free radicals: biological implications," Metal ions in Biological Systems, vol. 36, pp. 415-444, 1999.

[54] M. C. Houston, "The role of mercury and cadmium heavy metals in vascular disease, hypertension, coronary heart disease, and myocardial infarction," Alternative Therapies in Health and Medicine, vol. 13, no. 2, pp. S128-S133, 2007.

[55] B. Halliwell and J. M. C. Gutteridge, Free Radicals in Biology and Medicine, Oxford University Press, London, UK, 1999.

[56] S. Hussain, A. Atkinson, S. J. Thompson, and A. T. Khan, "Accumulation of mercury and its effect on antioxidant enzymes in brain, liver, and kidneys of mice," Journal of Environmental Science and Health-Part B Pesticides, Food Contaminants, and Agricultural Wastes, vol. 34, no. 4, pp. 645-660, 1999.

[57] V. Breinholt, S. T. Lauridsen, and L. O. Dragsted, "Differential effects of dietary flavonoids on drug metabolizing and antioxidant enzymes in female rat," Xenobiotica, vol. 29, no. 12, pp. 1227-1240, 1999.

[58] V. Benković, N. Orsolić, A. H. Knežević et al., "Evaluation of the radioprotective effects of propolis and flavonoids in gammairradiated mice: the alkaline comet assay study," Biological \& Pharmaceutical Bulletin, vol. 31, no. 1, pp. 167-172, 2008.

[59] V. Benković, A. H. Knežević, N. Orsolić et al., "Evaluation of radioprotective effects of propolis and its flavonoid constituents: in vitro study on human white blood cells," Phytotherapy Research, vol. 23, no. 8, pp. 1159-1168, 2009.

[60] F. A. Resende, C. P. da Silva Almeida, W. Vilegas, and E. A. Varanda, "Differences in the hydroxylation pattern of flavonoids alter their chemoprotective effect against direct- and indirect-acting mutagens," Food Chemistry, vol. 155, pp. 251255, 2014.

[61] S. J. S. Flora, "Structural, chemical and biological aspects of antioxidants for strategies against metal and metalloid exposure," Oxidative Medicine and Cellular Longevity, vol. 2, no. 4, pp. 191-206, 2009.

[62] S. J. S. Flora and V. Pachauri, "Chelation in metal intoxication," International Journal of Environmental Research and Public Health, vol. 7, no. 7, pp. 2745-2788, 2010.

[63] O. Ciftci, I. Ozdemir, N. Vardi, A. Beytur, and F. Oguz, "Ameliorating effects of quercetin and chrysin on 2,3,7,8-tetrachlorodibenzo- $P$-dioxin-induced nephrotoxicity in rats," Toxicology and Industrial Health, vol. 28, no. 10, pp. 947-954, 2012.

[64] O. Ciftci, N. Vardi, and I. Ozdemir, "Effects of quercetin and chrysin on 2,3,7,8-tetrachlorodibenzo-p-dioxin induced hepatotoxicity in rats," Environmental Toxicology, vol. 28, no. 3, pp. 146-154, 2013. 


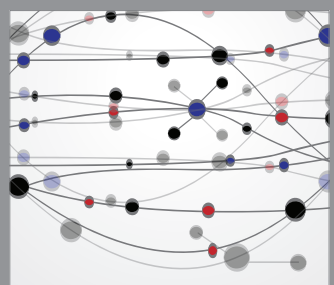

The Scientific World Journal
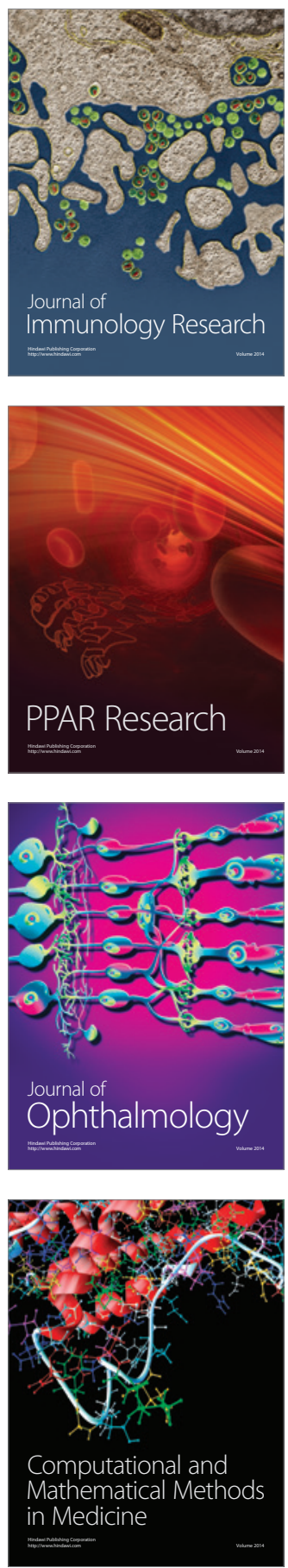

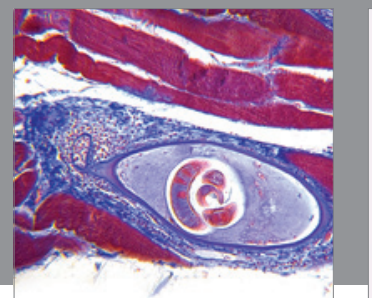

Gastroenterology

Research and Practice
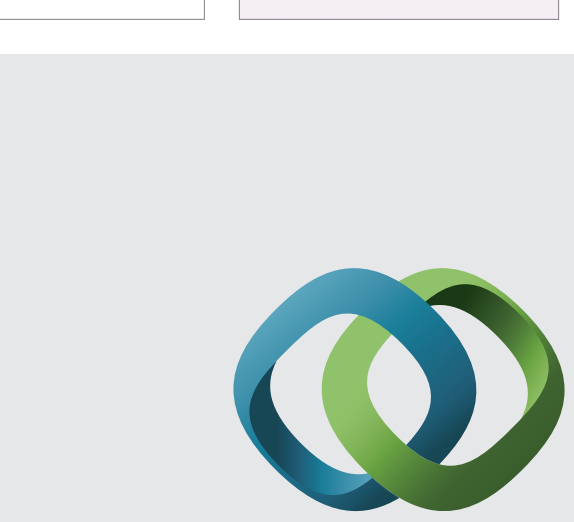

\section{Hindawi}

Submit your manuscripts at

http://www.hindawi.com
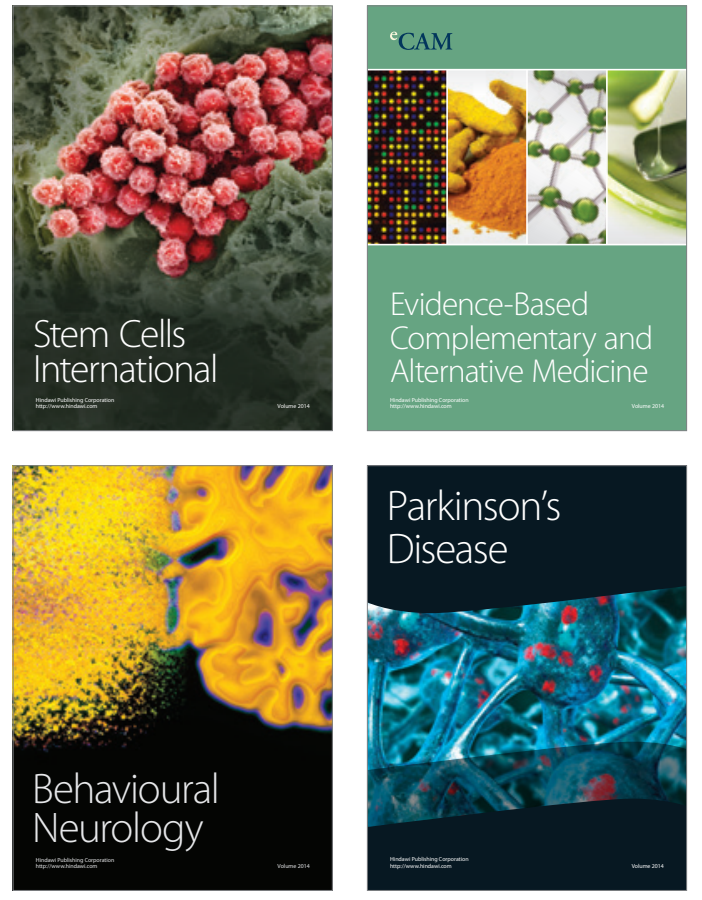
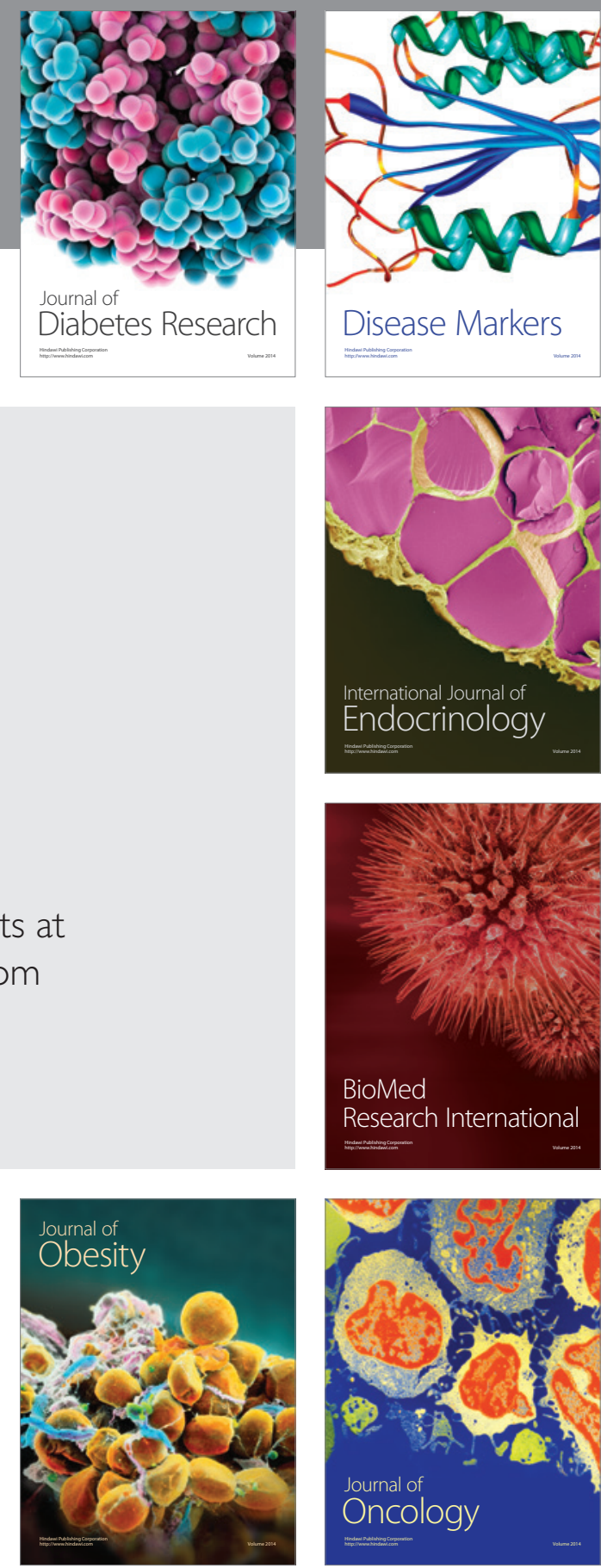

Disease Markers
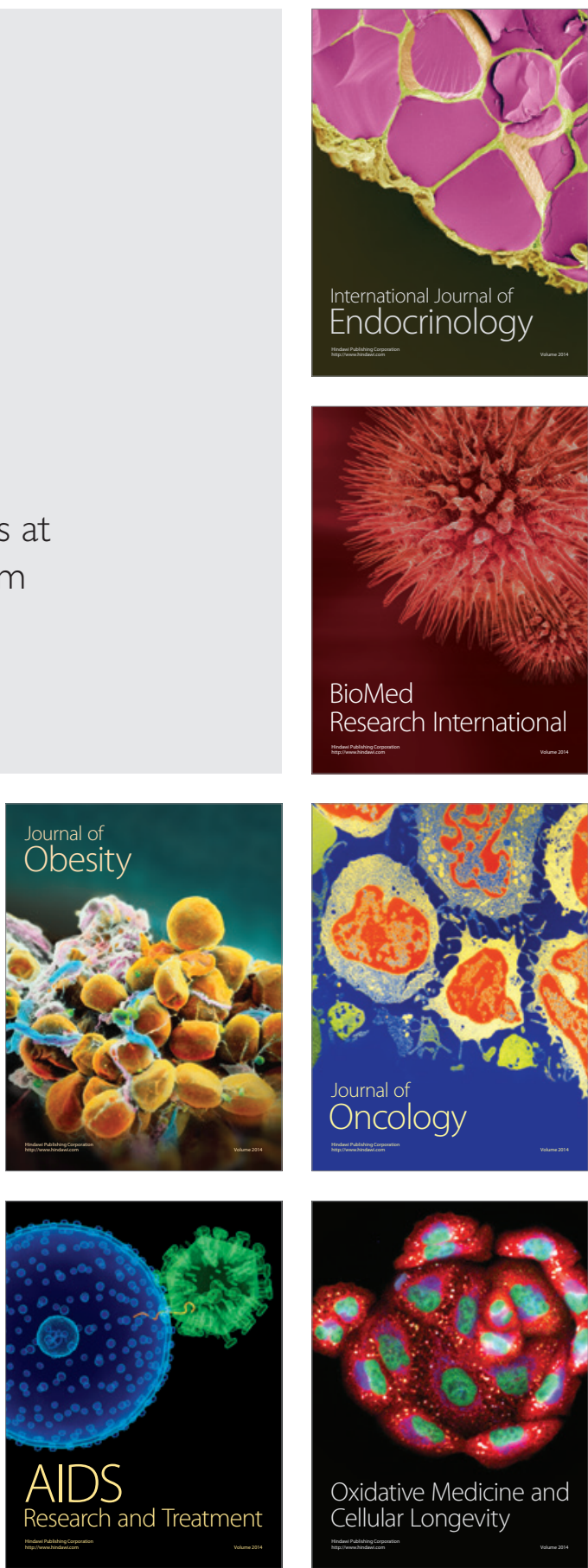